\title{
Novel Formaldehyde-Induced Modifications of Lysine Residue Pairs in Peptides and Proteins: Identification and Relevance to Vaccine Development
}

\author{
Thomas J.M. Michiels, * Christian Schöneich, Martin R.J. Hamzink, Hugo D. Meiring, \\ Gideon F.A. Kersten, Wim Jiskoot, and Bernard Metz
}

Cite This: Mol. Pharmaceutics 2020, 17, 4375-4385

Read Online

ACCESS | Lلll Metrics \& More | 国 Article Recommendations | (1) Supporting Information

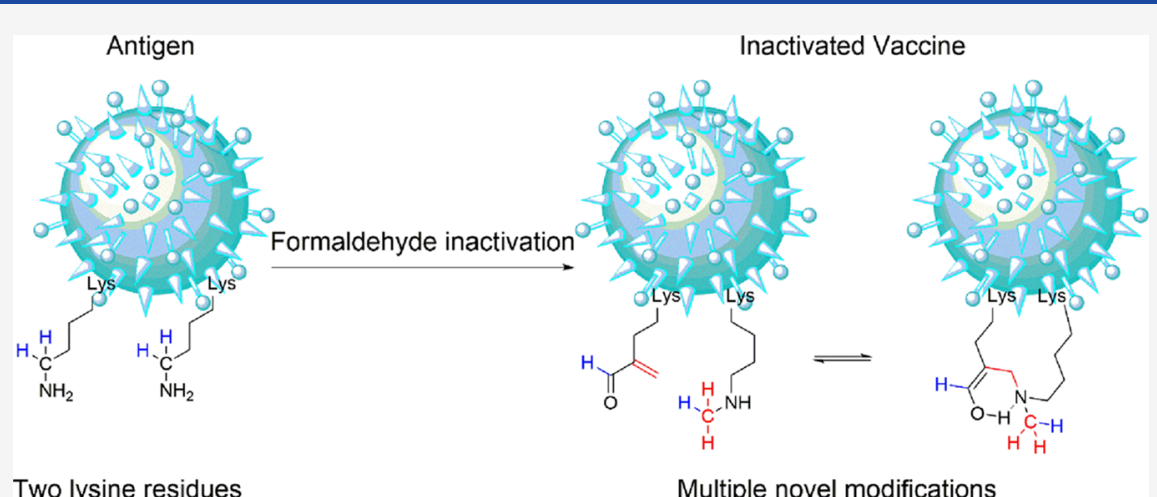

ABSTRACT: Formaldehyde-inactivated toxoid vaccines have been in use for almost a century. Despite formaldehyde's deceptively simple structure, its reactions with proteins are complex. Treatment of immunogenic proteins with aqueous formaldehyde results in heterogenous mixtures due to a variety of adducts and cross-links. In this study, we aimed to further elucidate the reaction products of formaldehyde reaction with proteins and report unique modifications in formaldehyde-treated cytochrome $c$ and corresponding synthetic peptides. Synthetic peptides (Ac-GDVEKGAK and Ac-GDVEKGKK) were treated with isotopically labeled formaldehyde $\left({ }^{13} \mathrm{CH}_{2} \mathrm{O}\right.$ or $\left.\mathrm{CD}_{2} \mathrm{O}\right)$ followed by purification of the two main reaction products. This allowed for their structural elucidation by (2D)-nuclear magnetic resonance and nanoscale liquid chromatography-coupled mass spectrometry analysis. We observed modifications resulting from $(i)$ formaldehyde-induced deamination and formation of $\alpha, \beta$-unsaturated aldehydes and methylation on two adjacent lysine residues and (ii) formaldehyde-induced methylation and formylation of two adjacent lysine residues. These products react further to form intramolecular cross-links between the two lysine residues. At higher peptide concentrations, these two main reaction products were also found to subsequently cross-link to lysine residues in other peptides, forming dimers and trimers. The accurate identification and quantification of formaldehyde-induced modifications improves our knowledge of formaldehyde-inactivated vaccine products, potentially aiding the development and registration of new vaccines.

KEYWORDS: formaldehyde, vaccines, antigens, NMR, mass spectrometry, structural elucidation, protein modification

\section{INTRODUCTION}

Formaldehyde is involved in a wide range of applications and processes. It is an important precursor in the synthesis of many chemicals, such as polymers and resins. ${ }^{1}$ Furthermore, the chemical is a potent disinfectant and sterilant. It is either obtained as a $37 \mathrm{wt} \%$ aqueous solution (known as formalin, usually stabilized with $10-15 \mathrm{wt} \%$ methanol) or vaporized from paraformaldehyde. As a disinfectant, it is effective against a wide variety of bacteria, fungi, and viruses. ${ }^{2}$ In addition to disinfecting equipment, formaldehyde is also used in other medical applications, for instance in dentistry. ${ }^{3}$ In histology and pathology, it is used as a fixation agent. ${ }^{4}$ In pharmaceutical applications, formaldehyde inactivation of antigens remains an important method for chemical inactivation of pathogens (reviewed elsewhere ${ }^{5}$ ) in the production of vaccines almost a century after its discovery. ${ }^{6}$ Marketed vaccines that are inactivated this way range from toxins (e.g., diphtheria toxin and tetanus toxin) to viruses (such as the poliovirus) and bacteria (such as whole-cell Bordetella pertussis vaccines) ${ }^{6-8}$ Formaldehyde inactivation also has potential for the develop-

Received: August 18, 2020

Revised: September 23, 2020

Accepted: September 23, 2020

Published: October 5, 2020

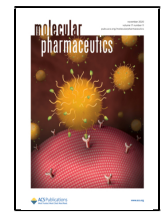


ment of new vaccines, such as enteroviruses (i.e., enterovirus $71^{9}$ and coxsackieviruses ${ }^{10}$ ) or coronaviruses (i.e., SARS-CoV$\left.1^{11}\right)$. Nevertheless, some formaldehyde-inactivated vaccine concepts have failed dramatically, such as the formaldehydeinactivated respiratory syncytial virus (RSV) vaccine, which enhanced the severity of RSV. ${ }^{5}$ Recently, this has been linked with the usage of suboptimal concentrations of formaldehyde, resulting in misfolding of the RSV fusion protein. ${ }^{12,13}$ This failure underlines the importance of product characterization and a general understanding of the mechanisms involved. The use of formaldehyde itself in vaccine production is sometimes a source of criticism because of its toxicity; ${ }^{14}$ however, formaldehyde is also an endogenous product in various metabolic processes in vivo and present at higher concentrations in the human body than in vaccines. ${ }^{15}$ It has been shown that endogenous formaldehyde induces immunogenic adducts; increased immunogenicity of formaldehyde-treated proteins is also observed in some vaccine products. ${ }^{16,17}$ The mechanism of formaldehyde-mediated inactivation and other formaldehyde reactions with proteins and amino acids has been studied by several groups. ${ }^{18-26}$ As formaldehyde is mixed with a solution containing proteins, imine and hydroxymethyl adducts are formed on amines, amides, and thiols. These then react further with other amino acid residues in the mixture such as tyrosine and arginine residues. This results in intermolecular (with other proteins or amino acids in the solution) and intramolecular cross-links. ${ }^{19}$ An overview of the most common formaldehyde-induced modifications is depicted in Table S1. Although a lot of progress has been made in the identification of formaldehyde-induced modifications, the complexity and heterogeneity of the reaction products still hinder a complete understanding of the processes involved. Thorough vaccine product characterization and understanding is key to monitoring batch-to-batch consistency. If the various chemical modifications and the degree of these modifications are known, batch release could be based on in vitro tests in a so-called consistency approach, instead of traditional in vivo release tests, measuring immunogenicity and (absence of) residual toxicity. ${ }^{27-30}$ Moreover, better understanding of formaldehyde-inactivated vaccines can aid the development and registration of new vaccines.

In previous work, we have analyzed the influence of formaldehyde modifications on the kinetics of proteolytic digestion of various model proteins. ${ }^{31}$ To identify formaldehyde-induced modifications in diphtheria toxoid or model proteins, such as cytochrome c, proteins were treated with aqueous solutions of $\mathrm{CH}_{2} \mathrm{O}$ or $\mathrm{CD}_{2} \mathrm{O}^{20}$ After incubation, the resulting mixtures were pooled in a 1:1 ratio. Subsequent protease digestion was used to obtain peptides that were analyzed using nanoscale liquid chromatography-coupled mass spectrometry (LC-MS). Classic formaldehyde modifications yield mass spectral doublet peaks with a $2 \mathrm{Da}$ mass difference or a multiple of $2 \mathrm{Da}^{18,20}$ with equal intensities. The structure of these formaldehyde modifications in cytochrome $\mathrm{c}$ has been assigned. ${ }^{31}$ However, several atypical spectral doublet peaks were observed that could not be addressed to these classic formaldehyde modifications.

In this study, we aim to further elucidate the reaction products of formaldehyde with proteins and report new modifications in formaldehyde-treated cytochrome $c$ and corresponding synthetic peptides. Synthetic peptides were treated with isotopically labeled formaldehyde $\left({ }^{13} \mathrm{CH}_{2} \mathrm{O}\right.$ or $\mathrm{CD}_{2} \mathrm{O}$ ) followed by purification of the two main reaction products. This allowed their structural elucidation using nuclear magnetic resonance (NMR) and nanoscale LC-MS analysis. These modifications involved (i) formaldehydeinduced deamination and formation of vinylic aldehydes and methylation on two adjacent lysine residues and (ii) formaldehyde-induced methylation and formylation of two adjacent lysine residues. At higher peptide concentrations, these two main reaction products were found to subsequently cross-link to lysine residues in other peptides, forming dimers and trimers.

\section{MATERIALS \& METHODS}

Synthetic peptides were purchased from Pepscan with $>95 \%$ purity as trifluoroacetic acid (TFA) salt. In a typical reaction, the peptides were dissolved in water (LC-MS grade; Biosolve) and added to a $100 \mathrm{mM}$ phosphate buffer ( $\mathrm{pH} 7.4$, obtained as a $1 \mathrm{M}$ solution from Sigma-Aldrich) containing $120 \mathrm{mM}$ formaldehyde (Sigma-Aldrich). The reaction mixture was then placed at $40{ }^{\circ} \mathrm{C}$, typically for 2 days. To stop the reaction and allow for nanoscale LC-MS analysis, $1 \mu \mathrm{L}$ aliquots were diluted in $1 \mathrm{~mL}$ of $0.1 \mathrm{vol} \%$ formic acid (Merck) or $10-\mu \mathrm{L}$ aliquots added to $90 \mu \mathrm{L} 1$ vol \% formic acid for conventional LC-MS. To stop the reaction and allow for purification, the $\mathrm{pH}$ of the mixture would be adjusted to $\sim 2$ by addition of 10 vol \% TFA (Sigma-Aldrich).

Reductive Methylation. Solutions of synthetic AcGDVEKGKK and Ac-GDVEKGKKIFVQ (1 mM) were treated with $123 \mathrm{mM}$ formaldehyde $\left(\mathrm{CH}_{2} \mathrm{O}\right)$ in phosphatebuffered saline (Gibco) with a total volume of $100 \mu \mathrm{L}$. After 4 days of incubation at $37^{\circ} \mathrm{C}$, an aliquot was taken for nanoscale LC-MS analysis (diluted $1: 100$ in 0.1 vol \% FA). Subsequently, $10 \mu \mathrm{L}$ of $1.23 \mathrm{M} \mathrm{NaBH}_{3} \mathrm{CN}$ and another 10 $\mu \mathrm{L}$ of $1.23 \mathrm{M}$ formaldehyde were added, and the samples were incubated for $30 \mathrm{~min}$ at room temperature after which another sample was taken.

Purification. Purification was achieved by reducing the total reaction volume 10 -fold by vacuum concentration using an Eppendorf vacuum centrifuge. The reaction products were separated after subsequent injections of $20 \mu \mathrm{L}$ of the sample onto an XSelect Peptide CSH C18, $130 \AA$ A $5 \mu \mathrm{m}, 4.6 \mathrm{~mm} \times$ $250 \mathrm{~mm}$ semipreparative column (Waters) using an Agilent 1290 Infinity II high-performance LC (HPLC) system with $\mathrm{UV}$ detection at $215 \mathrm{~nm}$. Eluent A consisted of water with 0.02 vol \% TFA, and eluent B consisted of 80 vol \% acetonitrile (LC-MS grade; Biosolve) with 20 vol \% water and 0.02 vol \% TFA. To separate the products, a 10 to $17 \%$ eluent $\mathrm{B}$ gradient in $6 \mathrm{~min}$ was used followed by 17 to $50 \% \mathrm{~B}$ in $1 \mathrm{~min}$. Fractions were collected manually and subsequently concentrated in the vacuum centrifuge to approximately $50 \mu \mathrm{L}$. For NMR analysis, $600 \mu \mathrm{L}$ of $\mathrm{D}_{2} \mathrm{O}$ (Sigma Aldrich) and $10 \mu \mathrm{L}$ of $\mathrm{D}_{2} \mathrm{O}$ containing 0.75 wt \% TMSP (Sigma Aldrich) were added. Products were stored at room temperature in NMR tubes at a $\mathrm{pH}<2.5$ due to residual TFA.

Stability of Product 3a. Purified 3a $(90 \mu \mathrm{L})$ (prepared from Ac-GDVEKGKK) was taken from the NMR tube $(15 \mu \mathrm{g})$ and mixed with $10 \mu \mathrm{L}$ of $1 \mathrm{M}$ phosphate buffer ( $\mathrm{pH}$ 7.4). The $\mathrm{pH}$ was verified using $\mathrm{pH}$ indicator paper. Immediately afterward, a $1 \mu \mathrm{L}$ aliquot was diluted into $1000 \mu \mathrm{L}$ of 0.1 vol $\%$ formic acid to quench the reaction. The remaining mixture was incubated at $40{ }^{\circ} \mathrm{C}$ for $18 \mathrm{~h}$ and sampled subsequently.

Acetaldehyde Reaction. Acetaldehyde (Sigma-Aldrich) was dissolved in $100 \mathrm{mM}$ phosphate buffer containing $0.1 \mathrm{mg} /$ $\mathrm{mL}$ Ac-GDVEKGAK, and the mixture was placed at room 


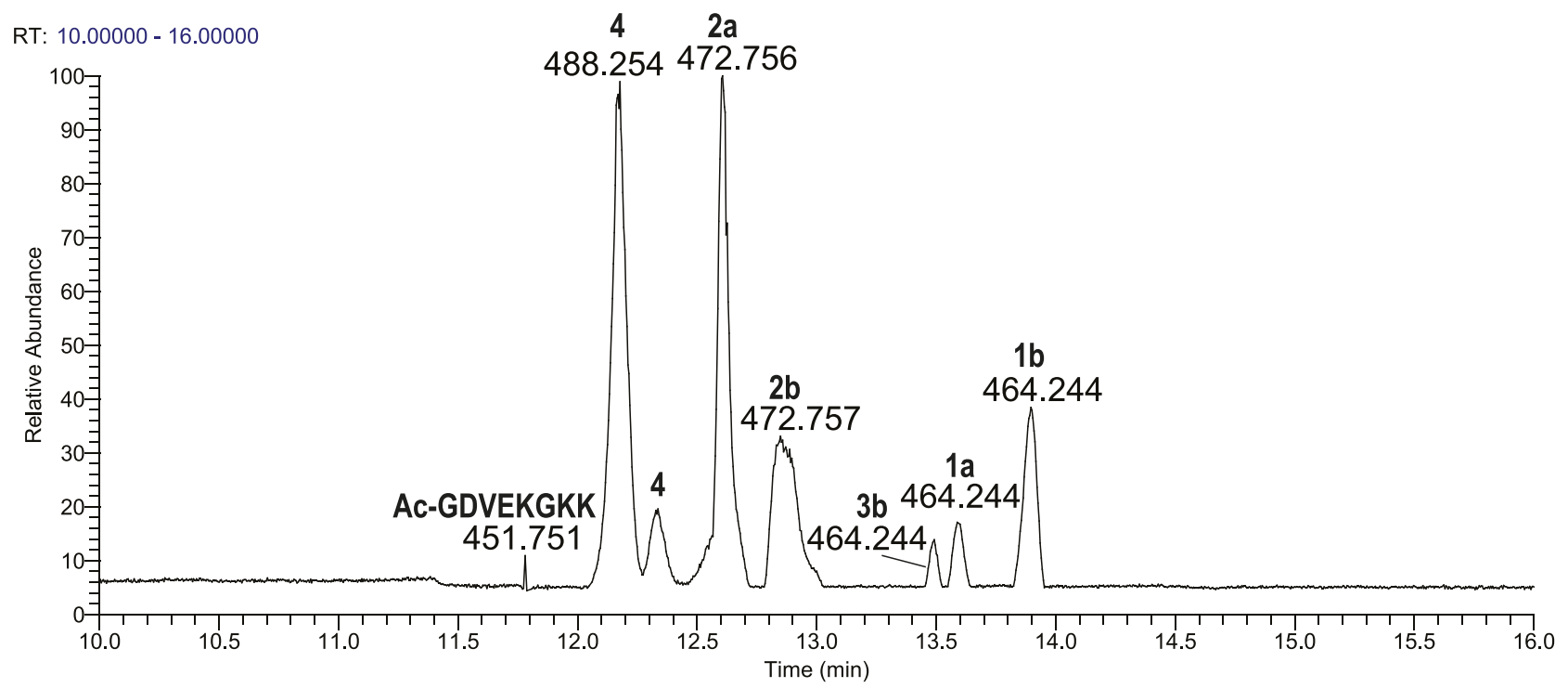

Figure 1. Representative nanoscale LC-MS base peak $\left(\mathrm{m} / z\right.$ 400-500) chromatogram of synthetic Ac-GDVEKGKK treated with aqueous $\mathrm{CH}_{2} \mathrm{O}$ for $46 \mathrm{~h}(z=2$ for all peaks). The exact regioisomers of the two peaks corresponding to product 4 could not be assigned.

temperature for 1 day. Subsequently, a $1 \mu \mathrm{L}$ aliquot was diluted into $1000 \mu \mathrm{L}$ of $0.1 \mathrm{vol} \%$ formic acid, and $1 \mu \mathrm{L}$ of an LC-MS sample of purified 8a (from Ac-GDVEKGAK treated with ${ }^{13} \mathrm{CH}_{2} \mathrm{O}$ ) was added as a ${ }^{13} \mathrm{C}$-labeled reference for nanoscale LC-MS analysis.

Nanoscale LC-MS. The peptides were analyzed by reversed-phase nanoscale LC-MS using a vented column system as described by Meiring et al. ${ }^{32}$ For this, an Agilent 1290 Infinity HPLC system was used in conjunction with a $100 \mu \mathrm{m}$ inner diameter (I.D.) trapping column packed to a bed length (L) of $20 \mathrm{~mm}$ with Reprosil-Pur C18-AQ $5 \mu \mathrm{m}$ particles and a $31 \mathrm{~cm}, \mathrm{~L} \times 50 \mu \mathrm{m}$ I.D. analytical column packed with Reprosil-Pur C18-AQ $3 \mu \mathrm{m}$ particles coupled to a gold-coated nanoelectrospray ionization spray tip with a $3.5 \mu \mathrm{m}$ tip diameter (all prepared in-house). The sample $(10 \mu \mathrm{L})$ was injected onto the trapping column. The trapping column was then washed with $0.1 \mathrm{vol} \%$ formic acid in water at a $5 \mu \mathrm{L} / \mathrm{min}$ flow rate for $10 \mathrm{~min}$. The gradient consisted of water with 0.1 vol \% formic acid (eluent A) and acetonitrile with 0.1 vol \% formic acid (eluent B). The gradient started at $4 \%$ B to $34 \%$ in $15 \mathrm{~min}$ followed by washing steps and re-equilibration. A flow restrictor was used to ensure a flow rate of $\sim 125 \mathrm{~nL} / \mathrm{min}$ through the analytical column. The LC system was coupled to an Orbitrap Fusion Lumos Tribrid mass spectrometer (Thermo Fisher). Analysis was done in data-dependent acquisition mode, with $\mathrm{MS}^{1}$ scans at 120,000 full width at half-maximum (FWHM) resolution from 300 to $1500 \mathrm{~m} / z$. Collision-induced dissociation (CID) fragmentation $\mathrm{MS}^{2}$ scans were measured in either iontrap or orbitrap mode, where the orbitrap resolution would be decreased to 7500 FWHM resolution for an increased acquisition speed. All $\mathrm{MS}^{1}$ orbitrap $\mathrm{m} / \mathrm{z}$ readouts were corrected using fluoranthene as an internal mass calibrant. Typical mass errors expected on $\mathrm{MS}^{1}$ were $<1$ and $<20 \mathrm{ppm}$ on $\mathrm{MS}^{2}$ (in orbitrap measurements). Note: for ease of reading, the number of digits behind the decimal separator in some figures is lower than those still considered accurate.

Conventional LC-MS. Reaction kinetics of AcGDVEKGKK, Ac-GDVEKGAK, Ac-GDVEAGKK, and AcGDVEKGKA were compared using conventional LC-MS. To this end, we used an Agilent Poroshell 120 EC C18 column $(2.1 \mathrm{~mm}$ I.D. $\times 50 \mathrm{~mm} \mathrm{~L})$ packed with $1.9 \mu \mathrm{m}$ particles with an Agilent 1200SL HPLC system coupled to an LTQ Orbitrap $\mathrm{XL}$ mass spectrometer (Thermo Fisher) with electrospray ionization. The same eluent system as with nanoscale LC was used with a 1 to $30 \% \mathrm{~B}$ in a 4-min gradient. The sample $(5 \mu \mathrm{L})$ at a concentration of $0.01 \mathrm{mg} / \mathrm{mL}$ peptide was injected. Measurements were performed in the ion trap at a normal scan rate from 300 to $900 \mathrm{~m} / z$.

Nuclear Magnetic Resonance. NMR experiments were carried out using a JEOL JNM-ECZ400S/L1 $400 \mathrm{MHz}$ NMR spectrometer in $\mathrm{D}_{2} \mathrm{O}$ with trimethylsilylpropanoic acid as internal reference. Default experimental settings as provided by JEOL were used. ${ }^{1} \mathrm{H}-\mathrm{NMR}$ spectra were recorded using Robust-5 water suppression (1064 scans). Standard ${ }^{13} \mathrm{C}$ spectra and DEPT-135 and DEPT-90 spectra were recorded until the signal/noise ratio was sufficient (typically, $>30,000$ scans). For heteronuclear single quantum coherence (HSQC) and heteronuclear multiple bond correlation (HMBC), the HSQC_wet and HMBC_wet experiments were used to suppress the water signal.

\section{RESULTS}

Detection of Unusual Formaldehyde Modifications in Cytochrome c. In a previous study, chemical modifications were identified in cytochrome $c$ after formaldehyde treatment. $^{31}$ However, some unexpected modifications were identified using the PEAKS Studio PTM module, which could not be explained. These observations triggered further investigation. In the previous study, proteins were treated with $\mathrm{CH}_{2} \mathrm{O}$ and $\mathrm{CD}_{2} \mathrm{O}$ separately, and after incubation, the samples were mixed at a $1: 1$ ratio and digested with the protease cathepsin S. Instead of the usual 1:1 ratio of the light and heavy peptide, the isotope pattern was skewed toward the light peptide (Figure S1). This observation triggered further investigation. Moreover, the mass increase after formaldehyde treatment was $+42.0106 \mathrm{Da}$, which commonly corresponds to acetylation $\left(+\mathrm{C}_{2} \mathrm{H}_{2} \mathrm{O}\right.$, on top of the standard acetylation of the cytochrome c N-terminus), but acetylation by formaldehyde is not obvious. As the mass increase between the light peptide 
Scheme 1. Ac-GDVEKGXK ( $\mathrm{X}=\mathrm{K}$ or $\mathrm{A}$ ) Reacts with Formaldehyde in Aqueous Buffer to Form 2a-b (a-b Represent Two Regioisomers), $\mathbf{l a}-\mathbf{b}$, and Tautomers $3 a-b^{a}$

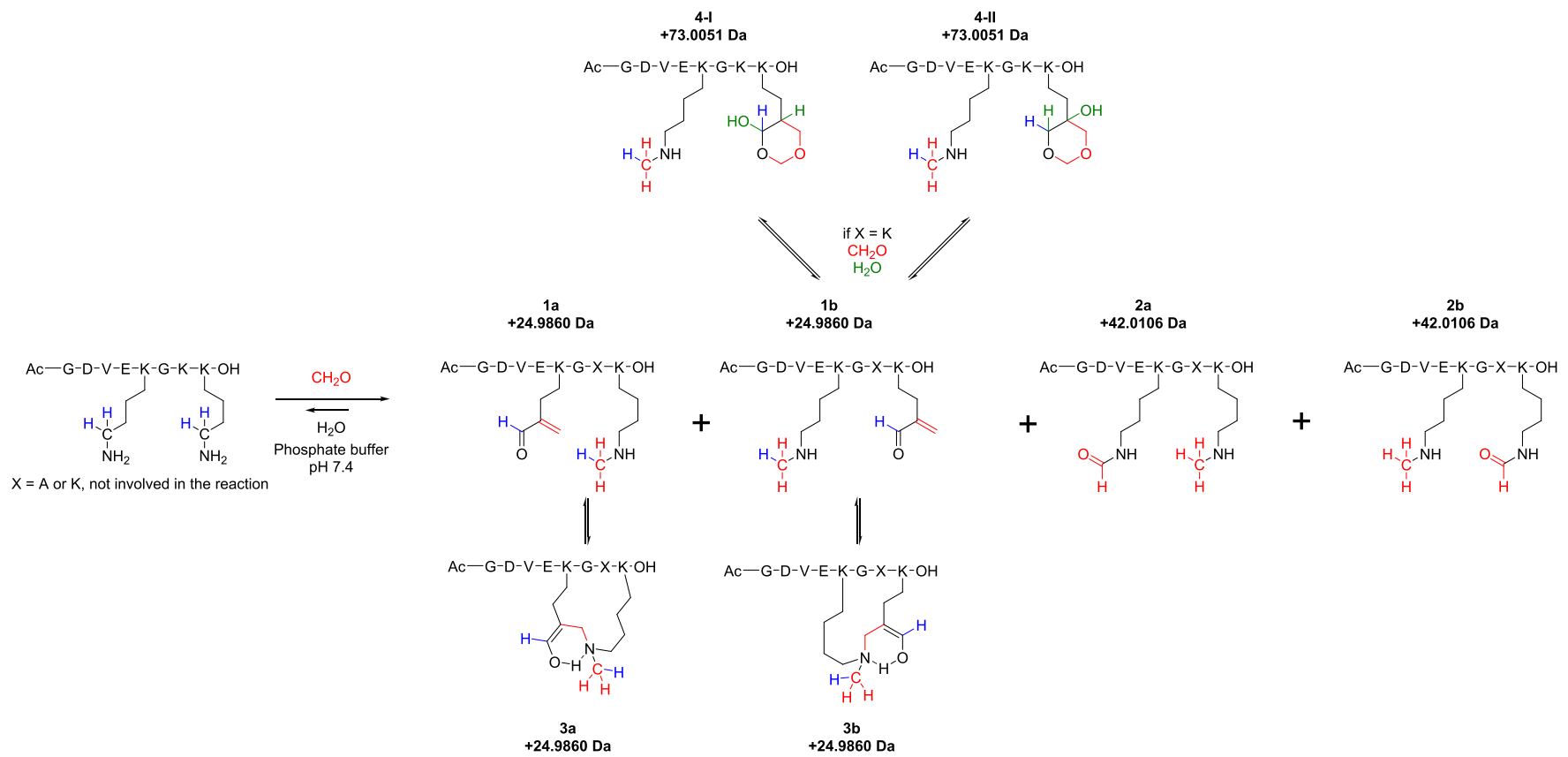

${ }^{a}$ If $X=K, 4-I$ and 4-II are formed as well. Reaction conditions: $100 \mathrm{mM}$ formaldehyde, $100 \mathrm{mM}$ phosphate buffer (pH 7.4) in water at $40{ }^{\circ} \mathrm{C}$ for $24 \mathrm{~h}$.

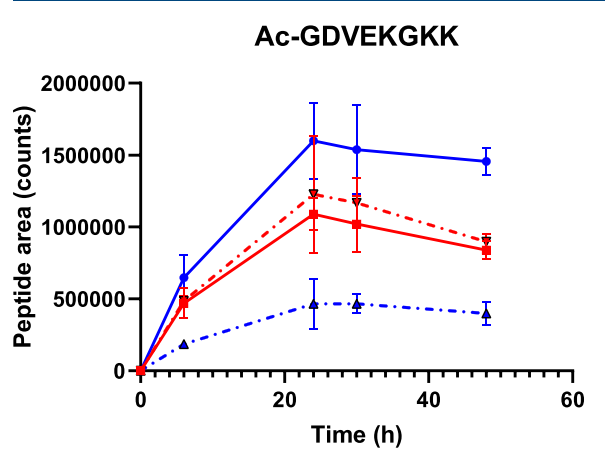

AC-GDVEKGKA

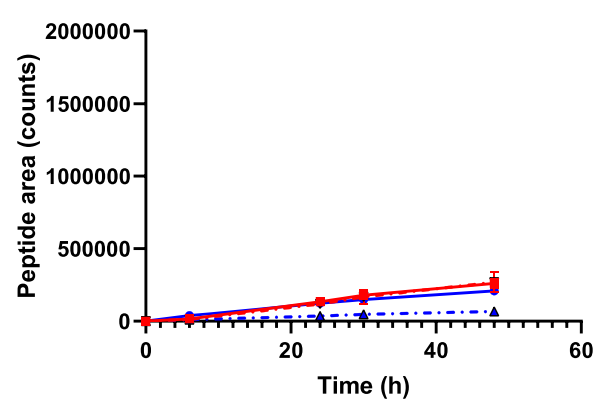

\section{Ac-GDVEKGAK}

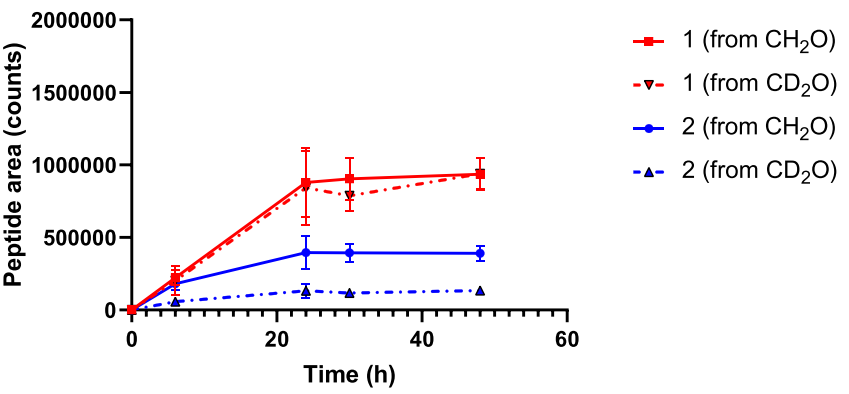

Ac-GDVEAGKK

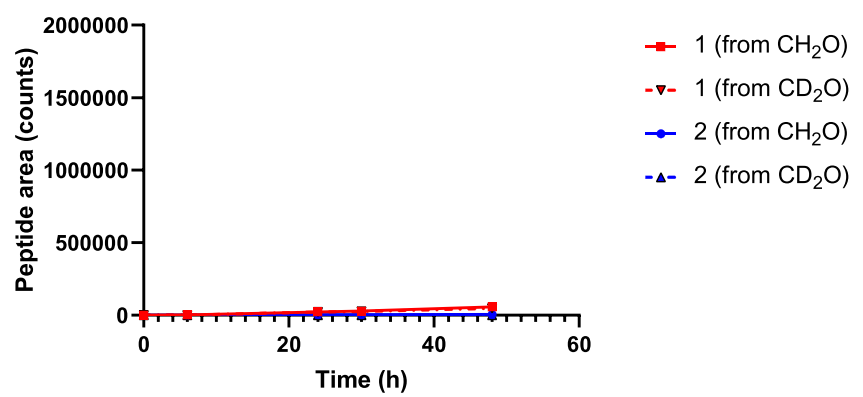

Figure 2. Comparison of the reaction between synthetic analogues of peptide Ac-GDVEKGKK (where one of the various lysine residues is replaced with an alanine residue) and the use of $\mathrm{CH}_{2} \mathrm{O}$ or $\mathrm{CD}_{2} \mathrm{O}$ on the formation of products 1 and 2 . The area of the regioisomers has been summed.

and the heavy peptide was $4 \mathrm{Da}$, two formaldehyde molecules (each containing two deuterons) must have been incorporated in the modification. Peptides derived from formaldehydetreated cytochrome $c$ that included this mass increase (+42.0106 Da) were Ac-GDVEKGKK, Ac-GDVEKGKKIFVQ, KGKKHKTGPNL, and AYLKK. All these peptides contain at least two lysine residues, making the involvement of two lysine residues in one modification or cross-link very likely.

Formaldehyde Modifications in Synthetic AcGDVEKGKK. To study this modification in detail, a synthetic peptide with the sequence Ac-GDVEKGKK was subjected to $120 \mathrm{mM}$ formaldehyde $\left(\mathrm{CH}_{2} \mathrm{O}\right.$ or $\left.\mathrm{CD}_{2} \mathrm{O}\right)$ in $100 \mathrm{mM}$ 

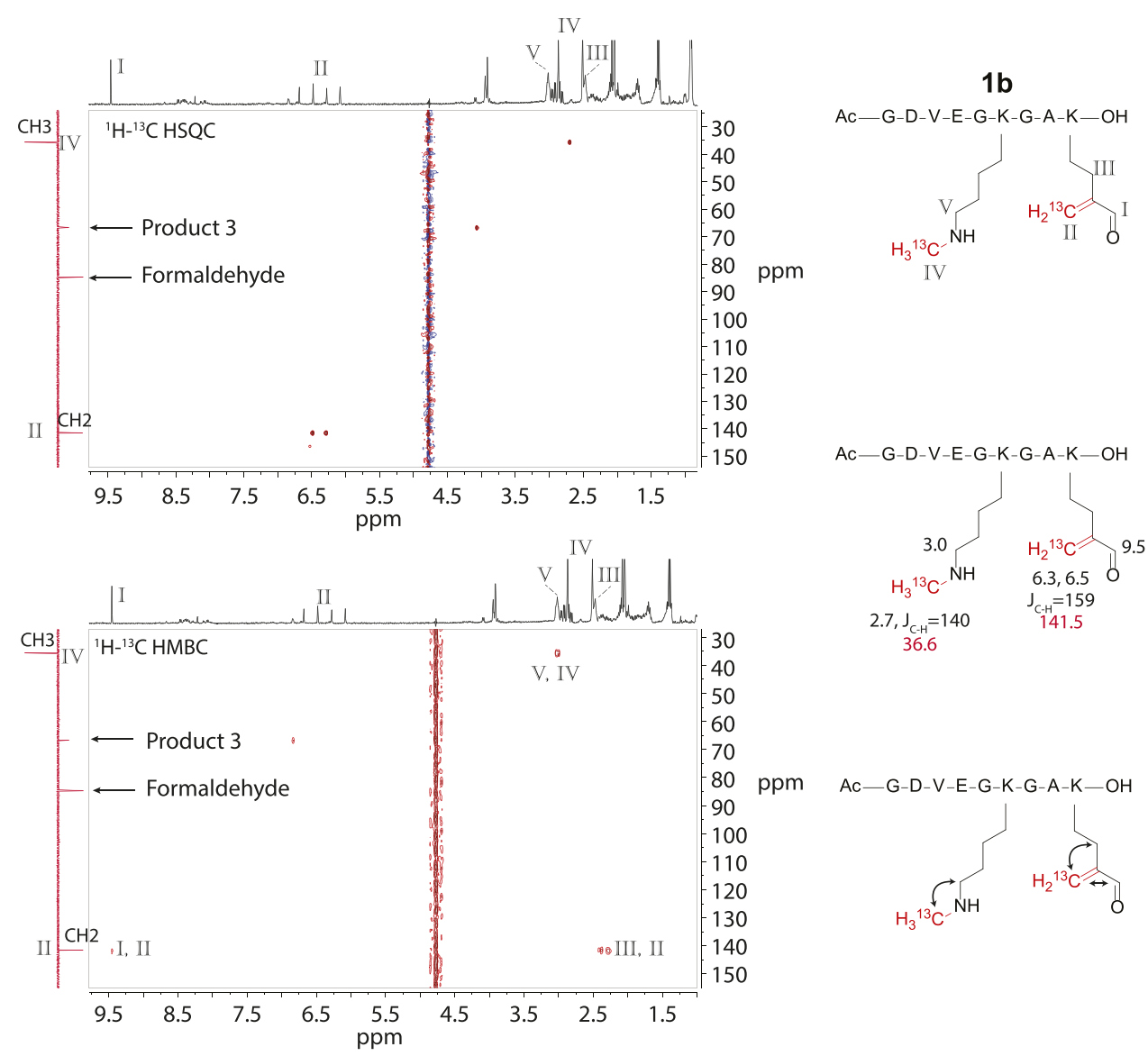

Figure 3. ${ }^{1} \mathrm{H}_{-}{ }^{13} \mathrm{C}$ HSQC and ${ }^{1} \mathrm{H}_{-}{ }^{13} \mathrm{C}$ HMBC of purified $\mathbf{1 b}$ obtained from a reaction with Ac-GDVEKGAK with ${ }^{13} \mathrm{C}$-labeled formaldehyde (adducts containing ${ }^{13} \mathrm{C}$ are marked in red, and ${ }^{13} \mathrm{C}$ NMR shifts are also marked in red). F1: DEPT-135 and F2: Robust5- ${ }^{1} \mathrm{H}$ (for water suppression) spectra.

phosphate buffer ( $\mathrm{pH}$ 7.4). Treatment of the native peptide resulted in the same modification with $\Delta M=+42.0106 \mathrm{Da}$, as observed for cytochrome c, along with a variety of other modifications. The most important of these other modifications were $\Delta M=+24.9840 \mathrm{Da}\left(+\left[\mathrm{C}_{2} \mathrm{O}\right]-[\mathrm{NH}]\right)$ and $\Delta M=$ $+73.0051 \mathrm{Da}\left(+\left[\mathrm{C}_{3} \mathrm{H}_{3} \mathrm{O}_{3}\right]-[\mathrm{N}]\right)$, where the latter is suggested to be an analogue in which an additional molecule has reacted with the former. A representative chromatogram is shown in Figure 1. Because of the complicated nature and the many reaction products formed, we decided to focus on the most important modifications, which form the basis for the other reaction products: $\Delta M=+24.9840 \mathrm{Da}(\mathbf{1} \mathbf{a}-\mathbf{b})$ and $\Delta M=$ $+42.0106 \mathrm{Da}$ (2a-b). The proposed structures for these modifications are depicted in Scheme 1. Experimental evidence for these structures is described below.

Reaction Kinetics. To investigate which lysine residues were involved in these formaldehyde modifications $(+24.9860$ and $+42.0106 \mathrm{Da})$, peptides with the general sequence AcGDVEXGXX were made, where $X=K$ or $A$ in all possible permutations. Treatment of the peptides that contained only one lysine did not result in the formation of significant additional peaks, with the exception of a small amount of the classic hydroxymethyl and imine adducts (data not shown). The other peptides showed different degrees of modification, where the extent of modification decreased in the following order: Ac-GDVEKGKK $\equiv$ Ac-GDVEKGAK > Ac-GDVEKGKA $\gg$ Ac-GDVEAGKK (Figure 2). The formation of $\mathbf{2}$ was diminished by the use of deuterated formaldehyde $(72 \%$ reduction for Ac-GDVEKGKK), while the effect of deuterated formaldehyde on the formation of $\mathbf{1}$ was less substantial. AcGDVEKGKK and Ac-GDVEKGAK form similar amounts of 2, with similar kinetics, but $\mathbf{1}$ was formed faster from AcGDVEKGAK. The use of $\mathrm{D}_{2} \mathrm{O}$ as a solvent instead of $\mathrm{H}_{2} \mathrm{O}$ did not affect the structure of the reaction products but slightly decreased the speed of the reaction (Figure S2).

Reductive Methylation of the Reaction Products. To elucidate the structures of reaction products 1 and 2 , the reaction mixture of Ac-GDVEKGKK with formaldehyde was subjected to reductive methylation by the addition of more formaldehyde and $\mathrm{NaCNBH}_{3}$. Unreacted Ac-GDVEKGKK was methylated 6 times, twice on each lysine residue. Although a variety of reaction products were formed, some of the main peaks observed were those corresponding to products $\mathbf{1}$ and $\mathbf{2}$ with three additional methyl groups. Thus, the original formaldehyde-induced adducts on $\mathbf{1}$ and $\mathbf{2}$ were both stable under mild reducing conditions, and three positions on the amine groups could still form imines and the corresponding methyl groups (Scheme S1). These results are consistent with the proposed structures $\mathbf{1}$ and $\mathbf{2}$.

Purification and Stability of Products 1 and 2. To enable NMR analysis of products 1 and 2 , the reaction mixture of ${ }^{13} \mathrm{CH}_{2} \mathrm{O}$ and Ac-GDVEKGAK was purified by reversedphase, preparative HPLC. Ac-GDVEKGAK instead of AcGDVEKGKK (found in cytochrome c) was used as the reactions were cleaner, which simplifies the purification. The products were reasonably stable in an aqueous solution at a 

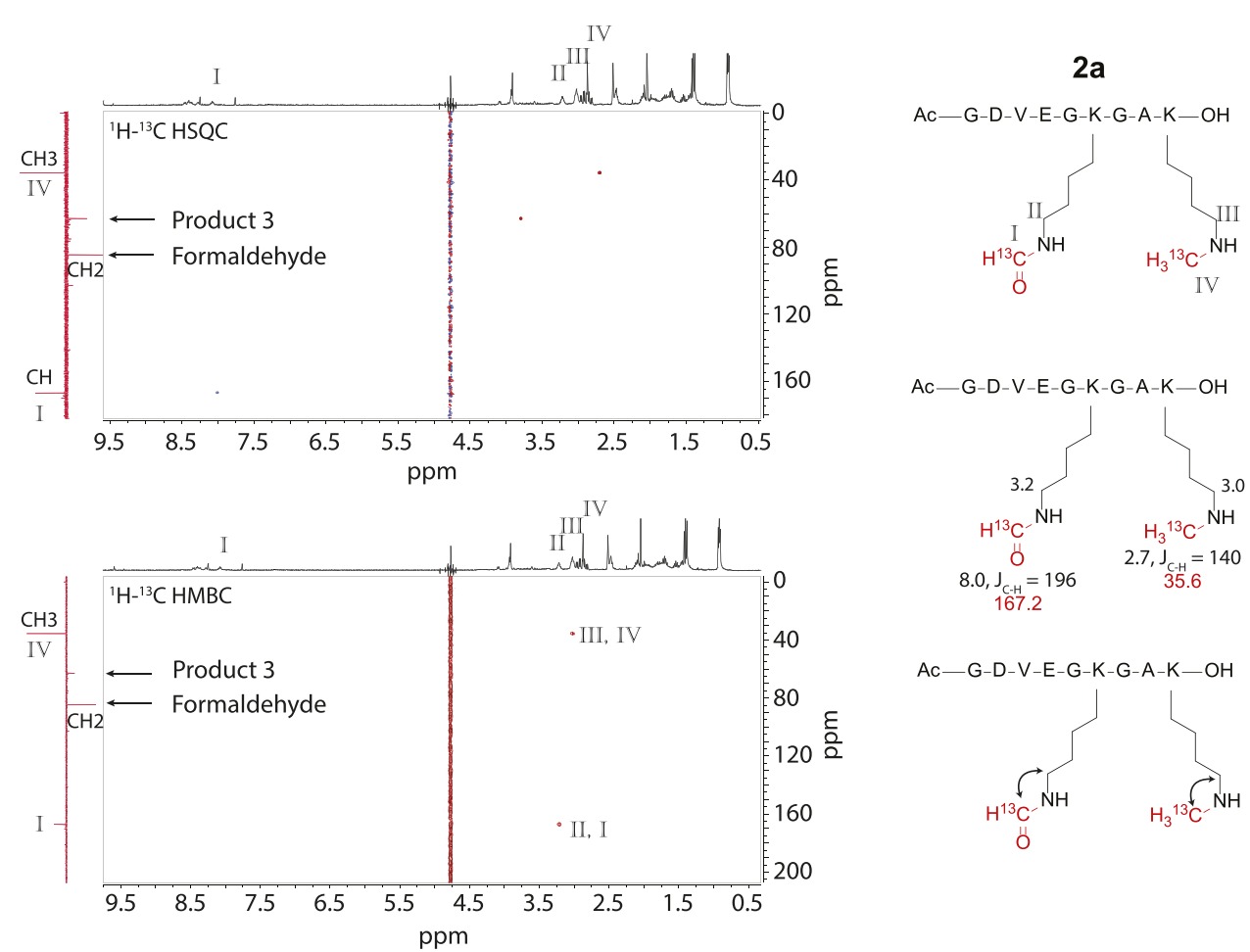

$A c-G-D-V-E-G-K-G-A-K-O H$ $20 \stackrel{\varepsilon}{2}$

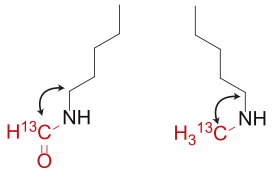

Figure 4. ${ }^{1} \mathrm{H}-{ }^{13} \mathrm{C}$ HSQC and ${ }^{1} \mathrm{H}^{-13} \mathrm{C}$ HMBC of purified 2a obtained from a reaction with Ac-GDVEKGAK with ${ }^{13} \mathrm{C}$-labeled formaldehyde (adducts containing ${ }^{13} \mathrm{C}$ are marked in red, and ${ }^{13} \mathrm{C}$ NMR shifts are also marked in red). F1: DEPT-135 and F2: Robust5- ${ }^{1} \mathrm{H}$ (for water suppression) spectra.

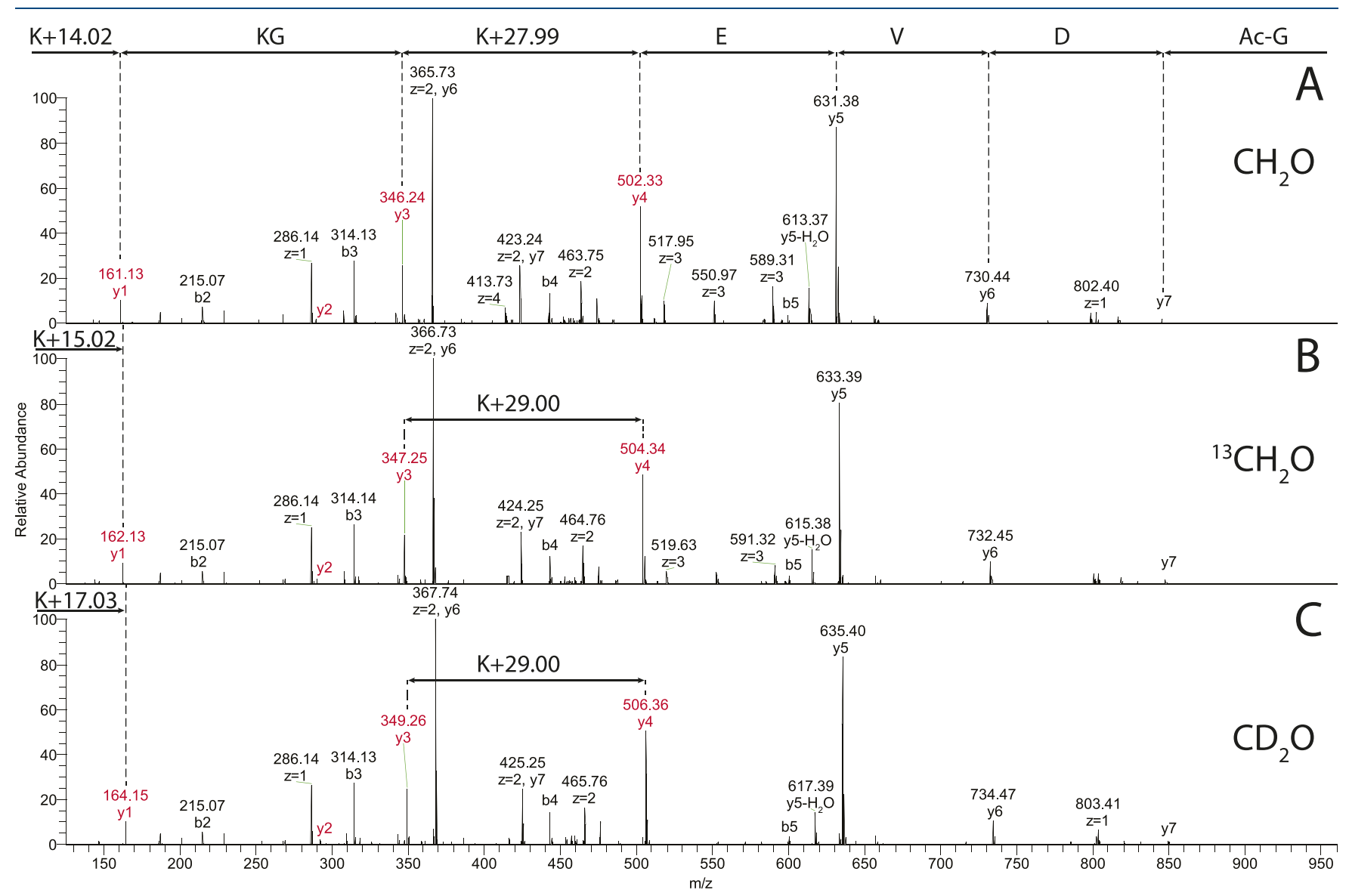

Figure 5. High-resolution $M S^{2}$ of $2 \mathrm{a}$ : $\mathrm{MS}^{2}$ spectrum of Ac-GDVEKGKK treated with $(\mathrm{A}) \mathrm{CH}_{2} \mathrm{O},(\mathrm{B}){ }^{13} \mathrm{CH}_{2} \mathrm{O}$, and $(\mathrm{C}) \mathrm{CD}_{2} \mathrm{O}$. 


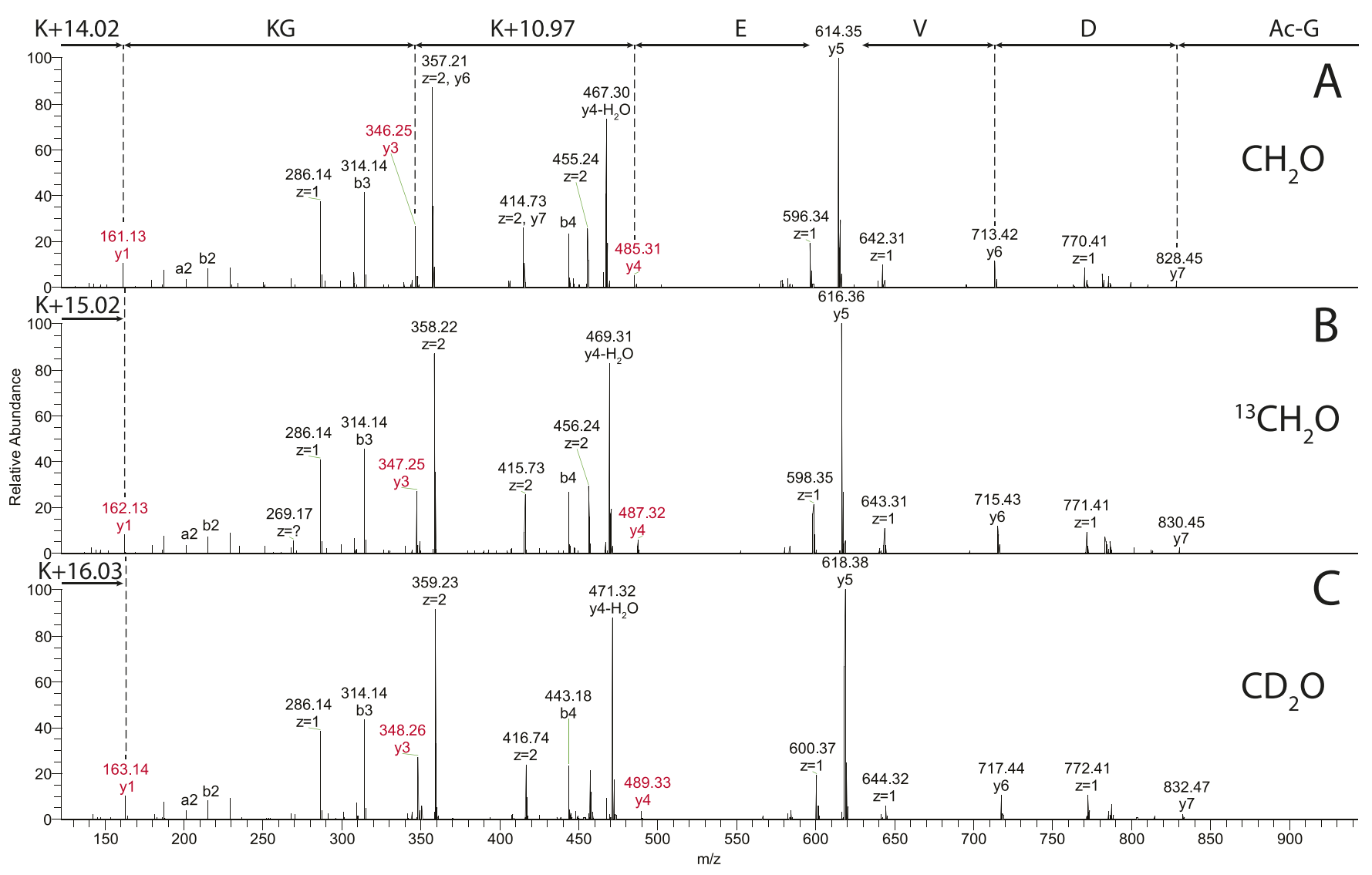

Figure 6. High-resolution $\mathrm{MS}^{2}$ of 1a: $\mathrm{MS}^{2}$ spectrum of Ac-GDVEKGKK treated with $(\mathrm{A}) \mathrm{CH}_{2} \mathrm{O},(\mathrm{B}){ }^{13} \mathrm{CH}_{2} \mathrm{O}$, and $(\mathrm{C}) \mathrm{CD}_{2} \mathrm{O}$.

low $\mathrm{pH}(<2.5)$ but not stable when drying, and thus, no dry products 1 and 2 could be obtained. Instead of completely removing the solvent, the solutions were concentrated with almost complete removal of the acetonitrile. The $\mathrm{pH}$ was typically $<3$ due to residual TFA. Typical yields (NMR) were around $10 \%$.

Despite product $2 \mathrm{a}$ being baseline separated from the chromatographically succeeding products $\mathbf{2 b}, \mathbf{1 a}$, and $\mathbf{1 b}$, the concentrated solution always contained some 1a (Figure S3A). Presumably, 1a was formed during concentration or other steps of the workup, after collection of $2 a$. Likewise, the purification of $\mathbf{1 a}$ always resulted in some 3 a being present, despite this chromatographic peak eluting at the same time as the removed product $2 \mathrm{a}$ (Figure S3 B). The presence of these impurities indicates that $1 \mathbf{a}$ can be formed from $2 \mathbf{a}$ and that $3 \mathbf{a}$ can be formed from 1a without the presence of additional formaldehyde.

To further investigate the stability of the reaction products, purified 2a (from Ac-GDVEKGKK) was placed in phosphate buffer at $\mathrm{pH} 7.4$ and stored at $37{ }^{\circ} \mathrm{C}$ for 1 day. Despite 2a being stable for weeks at low $\mathrm{pH}$, exposure to $\mathrm{pH} 7.4$ resulted in the formation of $\mathbf{1 a}$ and $\mathbf{1 b}$, although $\mathbf{1 a}$ was the more abundant degradation product (Figure S4).

NMR of Purified $1 \mathrm{~b}$ and $2 \mathrm{a}$. By using ${ }^{13} \mathrm{CH}_{2} \mathrm{O}$, sufficient material could be obtained to perform ${ }^{13} \mathrm{C}$ NMR experiments on two purified fractions containing $\mathbf{1 b}$ or $\mathbf{2}$ a derived from AcGDVEKGAK. However, only carbons originating from the formaldehyde modifications could be detected this way. To provide further structural information, ${ }^{1} \mathrm{H}$ (Robust-5 water suppression), DEPT, and HSQC were combined with HMBC (Figure 3 and Figure 4, described in detail in the Supporting
Information) and confirmed the structures of $\mathbf{1 b}$ and $\mathbf{2 a}$, respectively. Despite purification, nanoscaleLC-MS showed more than one peak, although the major product was $\mathbf{1 b}$. Indeed, in the NMR analysis, two ${ }^{13} \mathrm{C}$ signals were observed other than the peaks assigned to $\mathbf{1} \mathbf{b}$. These signals correspond to structure 3 (a tautomer of 1 ) and free formaldehyde.

$\mathrm{MS}^{2}$ Analysis of Products 1, 2, and 3. Subjecting AcGDVEKGKK, exposed to various isotopically enriched formaldehyde solutions $\left(\mathrm{CH}_{2} \mathrm{O},{ }^{13} \mathrm{CH}_{2} \mathrm{O}\right.$, and $\left.\mathrm{CD}_{2} \mathrm{O}\right)$, to $\mathrm{MS}^{2}$ analysis supported the NMR findings. Structures $\mathbf{1}$ and $\mathbf{2}$ were both found to exist as regioisomers, with mainly lysine- 5 and lysine- 8 being modified. Either lysine- 8 contained the methyl group (structures 1a and $\mathbf{2 a}$ ), with the other modification on lysine-5, or vice versa (structures $\mathbf{1 b}$ and $\mathbf{2 b}$ ) (Figure S5).

Fragmentation of $\mathbf{2 a}$ revealed that the y1 ion contains an additional +14.02 $\mathrm{Da}$, consistent with methylation of the Cterminal lysine (Figure 5A). ${ }^{13} \mathrm{C}$-labeled formaldehyde resulted in the $\mathrm{y} 1, \mathrm{y} 2$, and $\mathrm{y} 3$ ions to be $1.00 \mathrm{Da}$ heavier than the corresponding $\mathrm{y}$ ions resulting from regular formaldehyde treatment (Figure 5B). ${ }^{13} \mathrm{C}$-labeled formaldehyde resulted in a y4 ion with $\Delta M=+2.01 \mathrm{Da}$, which is in compliance with the proposed structure and the incorporation of two formaldehyde molecules on the peptide. Fragmentation of $\mathrm{CD}_{2} \mathrm{O}$-treated AcGDVEKGKK resulted in the $y 1$ ion being 3.02 Da heavier than that obtained after $\mathrm{CH}_{2} \mathrm{O}$ treatment, indicating that a deuteride was transferred from the modification on lysine- 5 to the $\mathrm{C}$-terminal lysine. Indeed, the mass difference between the $\mathrm{y} 3$ and $\mathrm{y} 4$ ions after $\mathrm{CD}_{2} \mathrm{O}$ treatment was $1.01 \mathrm{Da}(\Delta M=$ $K+29.00)$ compared with the $y 3$ and $y 4$ ions obtained after $\mathrm{CH}_{2} \mathrm{O}$ treatment $(\Delta M=K+27.99)$. 
Scheme 2. Proposed Mechanism for the Formation of 1 and 2

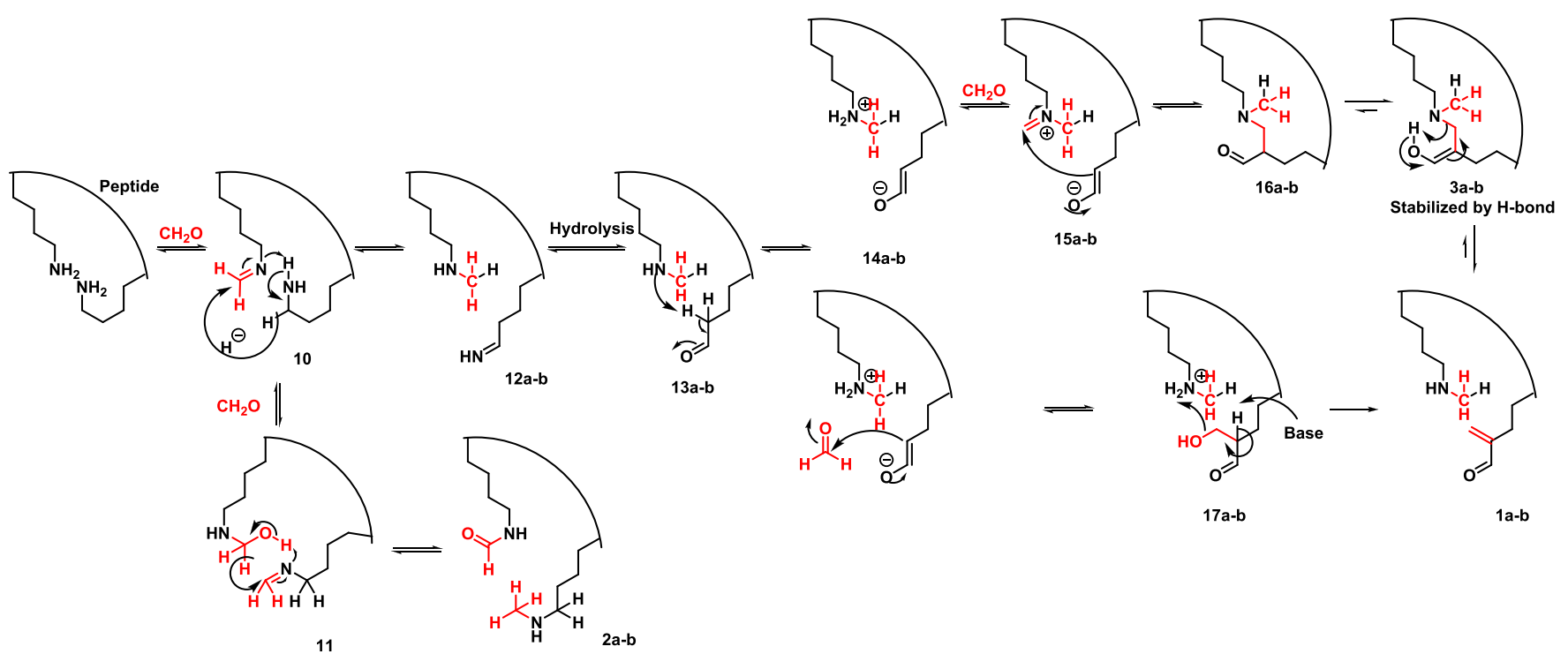

Fragmentation of $\mathrm{CH}_{2} \mathrm{O}$-treated 1a revealed methylation of lysine- 8 and a $\Delta M=+10.97 \mathrm{Da}\left(-\left[\mathrm{NH}_{3}\right]+[\mathrm{CO}]\right)$ on lysine-5 (Figure 6A). Contrary to $2 \mathrm{a}, \mathrm{CD}_{2} \mathrm{O}$-treated 1a showed a methylation of the C-terminal lysine with just 2 deuterium atoms (Figure 6C). The y4 ions of 1 a show that the C-terminal lysine contains a modification that is $2 \mathrm{Da}$ heavier when using $\mathrm{CD}_{2} \mathrm{O}$, corresponding to incorporation of both deuterium atoms on this residue.

$\mathrm{MS}^{2}$ analysis of the chromatographic peaks corresponding to structure $\mathbf{3 b}$ showed specific fragmentation resulting in only the $\mathrm{y} 4-\mathrm{H}_{2} \mathrm{O}$ ion (data not shown). The lack of backbone fragmentation between lysine-5 and lysine- 8 supports a cyclic structure. Ionization of $3 \mathbf{a}$ already resulted in significant fragmentation and detection of the $\mathrm{b} 4$ ion in the $\mathrm{MS}^{1}$ analysis.

$\mathrm{MS}^{2}$ of Product 4. Product 4 was only observed for the peptide containing three lysine residues. CID (ion trap detection) fragmentation showed identical ions for the two isobaric chromatographic peaks but at different relative intensities (Figure S6). This would fit having both the Markovnikov and anti-Markovnikov product present but with different intensities. From these data, the two isomers could not be assigned to a specific chromatographic peak.

Dimerization and Oligomerization. In order to obtain as much purified reaction product as possible, the reaction of formaldehyde was performed with various concentrations of synthetic Ac-GDVEKGAK. At the lowest peptide concentration $(0.25 \mathrm{mg} / \mathrm{mL})$, nanoscale LC-MS analysis revealed a few reaction products, mainly 1 and $\mathbf{2}$ (Figure S7). When the peptide concentrations were increased to as high as $5.75 \mathrm{mg} /$ $\mathrm{mL}$, reaction products other than 1 and 2 started to form. Some of the most intense peaks may belong to cross-linked structures, such as trimer 7 (Figure S7) and dimers 8 and 9. These proposed structures are based on their total mass $\left(\mathrm{MS}^{1}\right.$ mass error $<1 \mathrm{ppm}$ ). Both 1 and 2 seem to be involved in oligomerization, where 1 can form multiple reaction products, such as hydrogen-bond-stabilized enolates (7) or heteroDiels-Alder products (8). A variety of reaction products with different numbers of methyl groups were observed.

Reactions with Acetaldehyde. The formation of isobaric reaction products under the influence of acetaldehyde is described in the Supporting Information.

\section{DISCUSSION}

Two new groups of formaldehyde-induced modifications on peptide sequences containing (at least) two lysine residues were identified. The first modification involved methylation and formylation of the lysine pair, resulting in $\Delta M=+42.01$ $\mathrm{Da}$ (product 2 ). In the second modification, one lysine of the lysine pair was converted to an $\alpha, \beta$-unsaturated aldehyde, while the other lysine residue was methylated (product 1 ). Structure 1 could also form a tautomer where both lysine residues are cross-linked (product 3 ). While lysine-lysine cross-links in the form of aminals have been suggested, ${ }^{5}$ to our knowledge, no NMR evidence for formaldehyde-induced lysine-lysine crosslinks has been reported yet.

The formaldehyde modification (product 2) $(\Delta M=+42.01$ $\mathrm{Da})$ was not found in our previous studies, ${ }^{20}$ where we used proteins treated with either $\mathrm{CH}_{2} \mathrm{O}$ or $\mathrm{CD}_{2} \mathrm{O}$ in a $1: 1$ mixture. Hydroxymethyl adducts exchange their oxygen atom with the oxygen atom in water through the equilibrium with the corresponding imine. However, deuterons of the common formaldehyde-induced protein modifications were not expected to be exchanged. ${ }^{19}$ This assumption implies that formaldehyde-induced modifications are always present at an almost perfect $1: 1$ ratio. In our current study, we identified a new modification where slower reaction kinetics with deuterated formaldehyde resulted in a skewed isotope pattern. These reaction kinetics point to the transfer of a hydride (or deuteride) from one part of the molecule to another. This transfer would be the rate-limiting step in the formation of 2 . Our suggested mechanism for the formation of $\mathbf{2}$ (Scheme 2) involves the formation of an imine on the $\varepsilon-\mathrm{NH}_{2}$ group of one of two lysine residues and the corresponding hydroxymethyl on the other lysine residue. We propose that the nitrogen of the imine acts as a base, deprotonating the hydroxymethyl $\mathrm{OH}$; and subsequent transfer of the hydroxymethyl $\alpha$-hydride to the adjacent imine forms product 2 . This last step would explain the observed kinetic isotope effect, which is further supported by $\mathrm{MS}^{2}$ analysis of the deuterated $2 \mathrm{a}$, showing a methylated y1 ion $3 \mathrm{Da}$ heavier than its nondeuterated counterpart. NMR evidence for this structure is strong with ${ }^{1} \mathrm{H}$, DEPT-90, DEPT135, and ${ }^{1} \mathrm{H}_{-}{ }^{13} \mathrm{C} \mathrm{HMBC}$ supporting this structure. Formylation in combination with methylation by formaldehyde has been 
observed before in solutions of the amino acid ornithine but not on lysine, ${ }^{21}$ indicating that the orientation of the amino groups is pivotal for this reaction. Indeed, the spacing between the lysine residues was important for this reaction to occur; the fastest reaction rates were observed when two spacing amino acids were located between the two lysine residues.

The modification with $\Delta M=+24.98 \mathrm{Da}$ (1) was less affected by the use of deuterated formaldehyde. Our suggested mechanism for the formation of $\mathbf{1}$ (Scheme 2) again starts with formation of an imine on one of the lysine residues. However, instead of involvement of another formaldehyde molecule, the side chain of the nearby lysine residue is oxidized to an imine. The hydrogen atom of the lysine side chain is transferred to the imine adduct originating from formaldehyde to form intermediate 12. Subsequent hydrolysis of imine 12 results in aldehyde 13. Similar to the formation of 2 , this results in methylation of one lysine residue; however, when deuterated formaldehyde was used, not three but two deuterons were present on the methyl group, and the other hydrogen originates from the lysine side chain. Intermediate 13 has been observed by LC-MS. Tautomerization of 13 leads to enolate 14, which can then perform a nucleophilic attack on a formaldehyde molecule to give 17 . Subsequent $\beta$-elimination gives product 1 . Product 1 could tautomerize to form enol 3 . This enol could be stabilized by a hydrogen bond between the lysine nitrogen and the enol proton. Hydrogen-bond-stabilized enols are well described. ${ }^{33}$ The limited fragmentation of 3 during $\mathrm{MS}^{2}$ analysis further supports a cyclic structure, with a bridge between the two lysine residues, which hinders complete fragmentation of the $\mathrm{y} 4$ ion. The high amount of reactive intermediates would suggest that multiple reaction products could be formed through various pathways. Indeed, the NMR spectra of purified reaction products always contained some impurities, likely formed due to side reactions after purification. The main impurity in purified $\mathbf{2 a}$ is $\mathbf{3}$, a tautomer of $\mathbf{1}$, which happens to co-elute with $\mathbf{2 a}$. Furthermore, formaldehyde is present in the purified samples. While it is possible that this is due to incomplete removal of formaldehyde through the preparative HPLC, it is more likely that formaldehyde is released from the reaction products through equilibria, as formaldehyde is present in a similar amount. Storage at a low $\mathrm{pH}(<3)$ seemed to keep both products 1 and 2 stable for weeks probably because protonation of the amines decreases nucleophilicity and prevents them from acting as a Brønsted base, which could catalyze further reactions. Increasing the $\mathrm{pH}$ (to 7.4) resulted in relatively fast (days) conversion of 2 to 1 . Due to the reactivity of $\alpha, \beta$-unsaturated aldehydes, we expect these reaction products to react further when exposed to suitable nucleophiles in biological matrices. Indeed, the modification with $\Delta M=+24.98 \mathrm{Da}$ (1) was observed only in reactions with synthetic peptides, presumably, either because the modification is not formed in cytochrome $\mathrm{c}$ due to folding or because of the modified lysine residues reacting further with other amino acids to form other reaction products. As a large number of low-intensity side products were observed by nanoscale LCMS after formaldehyde treatment of a simple purified peptide, high reactivity of the reaction products combined with a more complicated protein would be a likely explanation for the difference we observed between peptide reactivity and the presence of these modifications in cytochrome c.

Product $\mathbf{4}$ is likely formed from $\mathbf{1 b}$ (Ac-GDVEKGKK), as the modification of lysine- 8 involves loss of a nitrogen atom, similar to product $\mathbf{1} \mathbf{b}$. The presence of the b7 ion supports methylation on either lysine-5 or lysine-7 and not lysine-8, while y1-related ions confirm modification of lysine- 8 by $\Delta M=$ $+58.9895 \mathrm{Da}$. Overall, product 4 is thought to be one of many reaction products that are eventually formed from 1 (or 2 ). Our suggested mechanism involves the formation of a hydroxymethylated product (1) as an intermediate (Scheme S2). Purification and structural elucidation of all reaction products present in this peptide-formaldehyde reaction mixture are beyond the scope of the present study; thus, no further purification and subsequent NMR analysis of $\mathbf{4}$ or other side products were attempted.

Several dimers and trimers were also observed. The most probable structures are suggested based on their accurate mass $(\Delta M<1 \mathrm{ppm})$, as $\mathrm{MS}^{2}$ fragmentation was not informative and purification and subsequent NMR analysis were deemed unfeasible. Because of the relatively simple reaction components being the peptide and formaldehyde, the possible combinations that lead to the same exact mass are limited. The bulk of the mass has to be made up by a number of peptides, where the residual mass is likely a combination of the main reaction products $\mathbf{1}$ and $\mathbf{2}$ along with other formaldehyde adducts. Trimer 7 is most likely a ring of three peptides, one peptide is one of the regioisomers of $\mathbf{1}$, and the other two are unmodified peptides. Although a linear structure with one aminal and a hetero-Diels-Alder product similar to dimer $\mathbf{8}$ is possible, a ring would be more thermodynamically favorable. Hydrogen bonding between the enol hydrogen and the amine could further stabilize this product. Aminals are not very stable in water, especially at a lower $\mathrm{pH}$, but in a ring system held together in a hetero-Diels-Alder product, this reaction could reverse, making the cyclic structure more favorable than a linear one. It is interesting that we managed to observe these aminals, as prior to analysis, aliquots of the reaction mixture were diluted in 0.1 vol \% formic acid, which would usually result in rapid hydrolysis of the aminal. ${ }^{34}$ Two species of dimers were observed, one consisting of reaction product of $\mathbf{2}$ with an unmodified peptide (9) and one consisting of a reaction product of $\mathbf{1}$ with an unmodified peptide (8). To get to the mass of product 9 , two extra formaldehyde molecules and three extra ring double bond equivalents are required. Thus, an aminal formed from the methylated lysine and lysine with an imine adduct, and a new ring involving the formylated lysine and a lysine with an imine adduct is the most logical explanation. Product 8 most likely consists of the product of a hetero-Diels-Alder reaction between an imine adduct on a lysine and the vinyl aldehyde of product $\mathbf{1}$ and an aminal connecting the other lysine residues. The imine corresponding to the aminal of $\mathbf{8}$ would have the same total mass, but it would be entropically favorable that the aminal forms first, so that the intramolecular Diels-Alder reaction can happen afterward as these reactions require decent activation energy. ${ }^{35,36}$ In reality, the reaction mixture probably contains a mixture of the cyclic reaction product and the imine, which are in equilibrium.

\section{- CONCLUSIONS}

Overall, we identified two new groups of formaldehydeinduced modifications of lysine residue pairs in peptides. Both the formylation/methylation modification pair and the $\alpha, \beta$ unsaturated aldehyde/methylation modification pair were involved in further cross-linking reactions, which should be addressed in future studies. These reaction products should be taken into consideration when analyzing biological samples 
exposed to exogenous or endogenous formaldehyde. Especially, biologicals, such as toxoid vaccines, are notoriously heterogeneous because of their formaldehyde modifications. $^{20,37}$ These newly discovered modifications could help us to further understand the nature of these vaccine products. As formaldehyde-induced modifications are linked to alterations in immunogenicity, ${ }^{16,17}$ their accurate identification and quantification may improve our understanding of formaldehyde-inactivated vaccine products, potentially aiding the development and registration of future formaldehyde-inactivated vaccines.

\section{ASSOCIATED CONTENT}

\section{SI Supporting Information}

The Supporting Information is available free of charge at https://pubs.acs.org/doi/10.1021/acs.molpharmaceut.0c00851.

Examples of the most common classic formaldehyde modifications; reaction kinetics of synthetic AcGDVEKGAK in $\mathrm{D}_{2} \mathrm{O}$; Chromatograms and spectra of structure 1 in cytochrome c; Chromatograms of purified 1a and 2a; high-resolution and CID fragmentation $\mathrm{MS}^{2}$ spectra comparing $\mathbf{2 a}$ and $\mathbf{2} \mathbf{b}$; base peak LC-MS chromatogram and representative averaged $\mathrm{MS}^{1}$ spectra of dimers and trimers; a detailed description of NMR spectra; a description of similar reactions with acetaldehyde instead of formaldehyde; Methylated products $\mathbf{1 a}$ and $\mathbf{2 a}$ after additional formaldehyde and reduction by $\mathrm{NaCNBH}_{3}$; proposed mechanism for the formation of 4 from $\mathbf{1 b}$; proposed reaction of peptide Ac-GDVEKGAK with acetaldehyde; chromatogram of acetaldehyde-treated Ac-GDVEKGAK; and $\mathrm{MS}^{2}$ comparison between products 1a and 5a (PDF).

\section{AUTHOR INFORMATION}

\section{Corresponding Author}

Thomas J.M. Michiels - Division of BioTherapeutics, Leiden Academic Centre for Drug Research (LACDR), Leiden University, 2333 CC Leiden, The Netherlands; Intravacc, Institute for Translational Vaccinology, 3721 MA Bilthoven, The Netherlands; 이이.org/0000-0003-1517-0312; Phone: +31307920584; Email: Thomas.michiels@ intravacc.nl

\section{Authors}

Christian Schöneich - Department of Pharmaceutical Chemistry, The University of Kansas, Lawrence, Kansas 66047, United States; orcid.org/0000-0001-5082-8672

Martin R.J. Hamzink - Intravacc, Institute for Translational Vaccinology, 3721 MA Bilthoven, The Netherlands

Hugo D. Meiring - Intravacc, Institute for Translational Vaccinology, 3721 MA Bilthoven, The Netherlands

Gideon F.A. Kersten - Division of BioTherapeutics, Leiden Academic Centre for Drug Research (LACDR), Leiden University, 2333 CC Leiden, The Netherlands; Intravacc, Institute for Translational Vaccinology, 3721 MA Bilthoven, The Netherlands

Wim Jiskoot - Division of BioTherapeutics, Leiden Academic Centre for Drug Research (LACDR), Leiden University, 2333 CC Leiden, The Netherlands
Bernard Metz - Intravacc, Institute for Translational Vaccinology, 3721 MA Bilthoven, The Netherlands; (1) orcid.org/0000-0001-6814-7656

Complete contact information is available at: https://pubs.acs.org/10.1021/acs.molpharmaceut.0c00851

\section{Funding}

This work was supported, in part, by the Ministry of Agriculture, Nature, and Food Quality, the Netherlands.

Notes

The authors declare no competing financial interest.

\section{ACKNOWLEDGMENTS}

The authors thank Joost Uittenbogaard and Maarten Danial for their advice, Marjolein Zohlandt for critical review of the manuscript, and Aldolfo Botana of JEOL for assistance with the NMR analysis.

\section{REFERENCES}

(1) Christjanson, P.; Pehk, T.; Siimer, K. Hydroxymethylation and polycondensation reactions in urea-formaldehyde resin synthesis. J. Appl. Polym. Sci. 2006, 100, 1673-1680.

(2) Rutala, W.; Weber, D. HICPAC Guideline for Disinfection and Sterilization in Healthcare Facilities. https://www.cdc.gov/ infectioncontrol/guidelines/disinfection/ (31-Jul-2020),

(3) Chandrashekhar, S.; Shashidhar, J. Formocresol, still a controversial material for pulpotomy: A critical literature review. J. Restor. Dent. 2014, 2, 114.

(4) Buesa, R. J. Histology without formalin? Ann. Diagn. Pathol. 2008, 12, 387-396.

(5) Delrue, I.; Verzele, D.; Madder, A.; Nauwynck, H. J. Inactivated virus vaccines from chemistry to prophylaxis: merits, risks and challenges. Expert Rev. Vaccines 2012, 11, 695-719.

(6) Glenny, A. T.; Hopkins, B. E. Diphtheria Toxoid as an Immunising Agent. Br. J. Exp. Pathol. 1923, 4, 283-288.

(7) Gupta, R. K.; Sharma, S. B.; Ahuja, S.; Saxena, S. N. The effects of different inactivating agents on the potency, toxicity and stability of pertussis vaccine. J. Biol. Stand. 1987, 15, 87-98.

(8) WHO Production and Control of Tetanus Vaccine: Module III: Principles of Tetanus Vaccine Production. (WHO/VSQ/94.4). (26th of March).

(9) Reed, Z.; Cardosa, M. J. Status of research and development of vaccines for enterovirus 71. Vaccine 2016, 34, 2967-2970.

(10) Stone, V. M.; Hankaniemi, M. M.; Laitinen, O. H.; SioofyKhojine, A. B.; Lin, A.; Diaz Lozano, I. M.; Mazur, M. A.; Marjomaki, V.; Lore, K.; Hyoty, H.; Hytonen, V. P.; Flodstrom-Tullberg, M. A hexavalent Coxsackievirus $\mathrm{B}$ vaccine is highly immunogenic and has a strong protective capacity in mice and nonhuman primates. Sci. Adv. 2020, 6, eaaz2433.

(11) Darnell, M. E.; Plant, E. P.; Watanabe, H.; Byrum, R.; St Claire, M.; Ward, J. M.; Taylor, D. R. Severe acute respiratory syndrome coronavirus infection in vaccinated ferrets. J. Infect. Dis. 2007, 196, 1329-1338.

(12) Killikelly, A. M.; Kanekiyo, M.; Graham, B. S. Pre-fusion F is absent on the surface of formalin-inactivated respiratory syncytial virus. Sci. Rep. 2016, 6, 34108.

(13) Zhang, W.; Zhang, L. J.; Zhan, L. T.; Zhao, M.; Wu, G. H.; Si, J. Y.; Chen, L.; Lin, X.; Sun, Y. P.; Lin, M.; Yu, C.; Fang, M. J.; Wang, Y. B.; Zheng, Z. Z.; Xia, N. S. The Optimal Concentration of Formaldehyde is Key to Stabilizing the Pre-Fusion Conformation of Respiratory Syncytial Virus Fusion Protein. Viruses 2019, 11, 628.

(14) Kata, A. A postmodern Pandora's box: Anti-vaccination misinformation on the Internet. Vaccine 2010, 28, 1709-1716.

(15) Mitkus, R. J.; Hess, M. A.; Schwartz, S. L. Pharmacokinetic modeling as an approach to assessing the safety of residual formaldehyde in infant vaccines. Vaccine 2013, 31, 2738-2743. 
(16) Nakamura, J.; Shimomoto, T.; Collins, L. B.; Holley, D. W.; Zhang, Z.; Barbee, J. M.; Sharma, V.; Tian, X.; Kondo, T.; Uchida, K.; Yi, X.; Perkins, D. O.; Willis, M. S.; Gold, A.; Bultman, S. J. Evidence that endogenous formaldehyde produces immunogenic and atherogenic adduct epitopes. Sci. Rep. 2017, 7, 10787.

(17) Metz, B.; Jiskoot, W.; Hennink, W. E.; Crommelin, D. J.; Kersten, G. F. Physicochemical and immunochemical techniques predict the quality of diphtheria toxoid vaccines. Vaccine 2003, 22, $156-167$.

(18) Metz, B.; Kersten, G. F.; Baart, G. J.; de Jong, A.; Meiring, H.; ten Hove, J.; van Steenbergen, M. J.; Hennink, W. E.; Crommelin, D. J.; Jiskoot, W. Identification of formaldehyde-induced modifications in proteins: reactions with insulin. Bioconjugate Chem. 2006, 17, 815822.

(19) Metz, B.; Kersten, G. F.; Hoogerhout, P.; Brugghe, H. F.; Timmermans, H. A.; de Jong, A.; Meiring, H.; ten Hove, J.; Hennink, W. E.; Crommelin, D. J.; Jiskoot, W. Identification of formaldehydeinduced modifications in proteins: reactions with model peptides. $J$. Biol. Chem. 2004, 279, 6235-6243.

(20) Metz, B.; Michiels, T.; Uittenbogaard, J.; Danial, M.; Tilstra, W.; Meiring, H. D.; Hennink, W. E.; Crommelin, D. J. A.; Kersten, G. F. A.; Jiskoot, W. Identification of formaldehyde-induced modifications in diphtheria toxin. J. Pharm. Sci. 2019, 109, 543-557.

(21) Kamps, J. J. A. G.; Hopkinson, R. J.; Schofield, C. J.; Claridge, T. D. W. How formaldehyde reacts with amino acids. Commun. Chem. 2019, 2, 126.

(22) Trezl, L.; Rusznak, I.; Tyihak, E.; Szarvas, T.; Szende, B. Spontaneous $\mathrm{N}$ epsilon-methylation and $\mathrm{N}$ epsilon-formylation reactions between L-lysine and formaldehyde inhibited by L-ascorbic acid. Biochem. J. 1983, 214, 289-292.

(23) Yamada, M.; Funaki, S.; Miki, S. Formaldehyde interacts with RNA rather than DNA: Accumulation of formaldehyde by the RNAinorganic hybrid material. Int. J. Biol. Macromol. 2019, 122, 168-173.

(24) Gold, T. B.; Smith, S. L.; Digenis, G. A. Studies on the influence of $\mathrm{pH}$ and pancreatin on 13C-formaldehyde-induced gelatin cross-links using nuclear magnetic resonance. Pharm. Dev. Technol. 1996, 1, 21-26.

(25) Toews, J.; Rogalski, J. C.; Clark, T. J.; Kast, J. Mass spectrometric identification of formaldehyde-induced peptide modifications under in vivo protein cross-linking conditions. Anal. Chim. Acta 2008, 618, 168-183.

(26) Toews, J.; Rogalski, J. C.; Kast, J. Accessibility governs the relative reactivity of basic residues in formaldehyde-induced protein modifications. Anal. Chim. Acta 2010, 676, 60-67.

(27) Halder, M.; Depraetere, H.; Delannois, F.; Akkermans, A.; Behr-Gross, M. E.; Bruysters, M.; Dierick, J. F.; Jungback, C.; Kross, I.; Metz, B.; Pennings, J.; Rigsby, P.; Riou, P.; Balks, E.; Dobly, A.; Leroy, O.; Stirling, C. Recommendations of the VAC2VAC workshop on the design of multi-centre validation studies. Biologicals 2018, 52, $78-82$.

(28) De Mattia, F.; Chapsal, J. M.; Descamps, J.; Halder, M.; Jarrett, N.; Kross, I.; Mortiaux, F.; Ponsar, C.; Redhead, K.; McKelvie, J.; Hendriksen, C. The consistency approach for quality control of vaccines - a strategy to improve quality control and implement 3Rs. Biologicals 2011, 39, 59-65.

(29) De Mattia, F.; Hendriksen, C.; Buchheit, K. H.; Chapsal, J. M.; Halder, M.; Lambrigts, D.; Redhead, K.; Rommel, E.; SchartonKersten, T.; Sesardic, T.; Viviani, L.; Ragan, I. The vaccines consistency approach project: an EPAA initiative. Pharmeur. Bio. Sci. Notes 2015, 2015, 30-56.

(30) Metz, B.; Jiskoot, W.; Mekkes, D.; Kingma, R.; Hennink, W. E.; Crommelin, D. J.; Kersten, G. F. Quality control of routine, experimental and real-time aged diphtheria toxoids by in vitro analytical techniques. Vaccine 2007, 25, 6863-6871.

(31) Michiels, T. J. M.; Meiring, H. D.; Jiskoot, W.; Kersten, G. F. A.; Metz, B. Formaldehyde treatment of proteins enhances proteolytic degradation by the endo-lysosomal protease cathepsin S. Sci. Rep. 2020, 10, 11535 .
(32) Meiring, H. D.; van der Heeft, E.; ten Hove, G. J.; de Jong, A. P. J. M. Nanoscale LC-MS(n): technical design and applications to peptide and protein analysis. J. Sep. Sci. 2002, 25, 557-568.

(33) Imashiro, F.; Maeda, S.; Takegoshi, K.; Terao, T.; Saika, A. Structure-dependent intermolecular hydrogen-bond effects on carbon-13 NMR chemical shifts in enol forms of 1,3-diketones. J. Am. Chem. Soc. 1987, 109, 5213-5216.

(34) Sawatzky, E.; Drakopoulos, A.; Rölz, M.; Sotriffer, C.; Engels, B.; Decker, M. Experimental and theoretical investigations into the stability of cyclic aminals. Beilstein J. Org. Chem. 2016, 12, 22802292.

(35) Carneiro de Oliveira, J.; Laborie, M. P.; Roucoules, V. Thermodynamic and Kinetic Study of Diels-Alder Reaction between Furfuryl Alcohol and N-Hydroxymaleimides-An Assessment for Materials Application. Molecules 2020, 25, 243.

(36) Otto, S.; Blokzijl, W.; Engberts, J. B. F. N. Diels-Alder Reactions in Water. Effects of Hydrophobicity and Hydrogen Bonding. J. Organ. Chem. 1994, 59, 5372-5376.

(37) Bayart, C.; Peronin, S.; Jean, E.; Paladino, J.; Talaga, P.; Borgne, M. L. The combined use of analytical tools for exploring tetanus toxin and tetanus toxoid structures. J. Chromatogr. B: Analyt. Technol. Biomed. Life Sci. 2017, 1054, 80-92. 